\title{
Differences in physician referral practices and attitudes regarding hereditary breast cancer by clinical practice location
}

Christine E. Koil, $M S^{1}$, Jessica N. Everett, $M S^{1}$, Leah Hoechstetter, $M S^{1}$, Rick E. Ricer, $M D^{2}$, and Karen M. Huelsman, $M S^{1}$

\begin{abstract}
Purpose: To compare physician referral practices and attitudes regarding hereditary breast cancer by clinical practice location. Methods: A self-administered survey of 214 physicians in Ohio's tri-state region. Results: Rural-practice physicians were less likely to have ever referred for an indication of hereditary breast cancer than urban- and suburban-practice physicians combined. Rural-practice physicians reported stronger barriers to referral, including distance, lack of awareness, lack of effective cancer risk reduction, and lack of patient interest.

Conclusion: These findings demonstrate a need for increased clinical genetics outreach, physician education, and public awareness of genetic services for hereditary breast cancer in rural areas. Genet Med 2003:5(5):364-369.
\end{abstract}

Key Words: genetics, breast cancer, physicians, referral, rural health

In the United States, more than 180,000 women are diagnosed with breast cancer each year. ${ }^{1}$ It is estimated that $5 \%$ to $10 \%$ of all breast cancers are hereditary, or caused by an inherited susceptibility gene. ${ }^{2,3}$ Inherited mutations in the BRCA1 and $B R C A 2$ genes are associated with a $55 \%$ to $85 \%$ lifetime risk for breast cancer, as well as a $16 \%$ to $60 \%$ lifetime risk for ovarian cancer. ${ }^{4-8}$ Interest in hereditary breast cancer risk notification and genetic testing is high in the general population. ${ }^{9,10}$ Furthermore, the demand for cancer genetics services is likely to grow as a result of increasing exposure in the media. In addition, several studies have demonstrated the efficacy of cancer prevention strategies, including prophylactic oophorectomy and mastectomy and chemoprevention, for women at high risk for developing breast and ovarian cancer. ${ }^{11-17}$

Community physicians identify their role in provision of genetic services for hereditary breast cancer as "gatekeeper" of specialist services. ${ }^{18-24}$ This includes taking a family history, identifying individuals at increased risk, and delivering primary level information. In addition, most community physicians see it as their responsibility to decide who should be referred to genetic service providers for further evaluation. Numerous factors have been shown to influence a physician's decision to refer patients for genetic services, including specialty, year of graduation from medical school, knowledge,

\footnotetext{
From the ${ }^{1}$ Division of Human Genetics, Cincinnati Children's Hospital Medical Center, Cincinnati, Ohio; ${ }^{2}$ Department of Family Medicine, University of Cincinnati, Cincinnati, Ohio.

Christine Koil, MS, Department of Obstetrics and Gynecology, MSC10 5580, 1 University of New Mexico, Albuquerque, NM 87131-0001.

Received: March 10, 2003.

Accepted: June 9, 2003.
}

DOI: 10.1097/01.GIM.0000086477.00766.C9 motivations and barriers to referral, and attitudes about genetic services. ${ }^{23,25-28}$

A preliminary study, which analyzed the patient demographics of women evaluated at our hereditary cancer center, showed that only $1 \%$ of patients evaluated to date were referred from surrounding rural counties (unpublished data, 2001). Based on population estimates of the center's genetic catchment region, we would have expected $15 \%$ of our patients to be rural residents. This implies that individuals who reside in rural areas are less likely to be referred by physicians for genetic services for hereditary breast cancer than their urban or suburban counterparts.

The purpose of this study was to assess physician attitudes and practices regarding referrals for genetic services for an indication of hereditary breast cancer and to determine whether clinical practice location influences attitudes and practices. Although previous studies have examined physician referral practices and attitudes for a variety of genetic indications, including inherited cancers, ${ }^{23,26,27}$ few have stratified sample groups by clinical practice location for comparison. The studies that have attempted this analysis have included low numbers of rural-practice physicians and concluded that no differences in referral practices or attitudes exist by geographic region. Therefore, we sampled a significant proportion of rural-practice physicians to characterize referral practices and attitudes among this group, as well as to compare these parameters to urban- and suburban-practice physicians.

\section{METHODS}

\section{Study population}

Southwest Ohio's tri-state region includes Southwestern Ohio, Southeastern Indiana, and Northern Kentucky. The Region is made up of the large metropolitan area of Cincinnati 
and numerous surrounding rural counties. Cancer genetics services in the region are exclusively available in an urban medical center in the metropolitan area. Rural counties in the region are within 60 miles of at least one metropolitan center, and their average population density is 65 persons per square mile.

Physicians, whose specialties included family practice, general practice, general surgery, internal medicine, obstetrics and gynecology, and oncology, were chosen for this study because of their potential interaction with adult female patients who have a personal or family history of breast cancer. The study sample was drawn from the Ohio and Kentucky Boards of Medical Licensure Directories, the Indiana Academy of Family Physicians Directory, and the Indiana State Medical Association Online Directory. Two-thirds of the study population was selected randomly from physicians whose directory addresses were listed in Hamilton County, Ohio, which includes the city of Cincinnati and surrounding suburbs. One-third of the study population was composed of randomly selected physicians with addresses listed in rural counties within a 60 -mile radius of Hamilton County. For the purposes of this study, rural counties were defined as having a population density of $<120$ persons per square mile based on U.S. Census 2000 data. Physicians were eligible for the study if they were engaged in direct adult patient care for at least 10 hours per week. This study was approved by the Institutional Review Board of Cincinnati Children's Hospital Medical Center.

\section{Questionnaire development and distribution}

Our hereditary cancer clinic mailed a self-administered questionnaire, stamped return envelope, and descriptive cover letter to 928 eligible physicians. Of those, 60 (6.5\%) were undeliverable, and $13(1.4 \%)$ were excluded due to lack of patient contact. Thus, there were 855 potential respondents. Potential respondents who did not return the questionnaire within six weeks were mailed a second questionnaire. After an additional eight weeks, the data set was closed. There was no financial incentive for completing the questionnaire.

The questionnaire was developed by the principal investigator, genetic counselors specializing in hereditary cancers, and primary care physicians. Questions about referral practices included the following: if physicians had ever referred for this indication, frequency of referral, reason for referral or nonreferral, and specialist of referral. We assessed physician attitudes about referral by measuring the influence of motivations and barriers to referral, which were similar to those used in previous peer-reviewed research. ${ }^{23,24,27,29}$ Physicians rated the strength of influence for motivations and barriers to referral using a five-point Likert scale ranging from "very influential" to "not influential at all." The questionnaire was piloted by clinicians in the areas of genetic counseling, oncology, surgery, and family practice.

Demographic data were collected in the questionnaire including gender, year of graduation from medical school, degree, and primary specialty. Information about the physicians' clinical practice location was also collected, including county, zip code, and self-reported descriptor of clinical practice location: urban, suburban, and/or rural. Physicians were encouraged to report demographic information for all clinical practice locations. Physicians were grouped retrospectively into clinical practice location groups for data analysis based on selfreported descriptor(s).

\section{Data analysis}

Data were analyzed using SAS for Windows, Version 8 . The study population was characterized using descriptive statistics. Frequency data were obtained for all categorical questions and compared between clinical practice location groups using chisquare analysis. All clinical practice location comparisons were limited to urban- and/or suburban-practice combined compared to rural-practice. Logistic regression analysis was used to control for demographic variables. The frequency of referrals in the last 12 months was converted from categorical to ordinal data. The mean ordinal values were compared between clinical practice location groups using the Wilcoxon Ranked Sum test for nonparametric data. Mean Likert values for each of the motivations and barriers to genetics referral were compared in the same manner. All quantitative analyses were considered to be significant when $P<0.05$.

\section{RESULTS}

\section{Characteristics of study population}

Of the 855 potential respondents, 239 (28\%) questionnaires were returned, 214 of which were completed and eligible, for an effective response rate of $25 \%$. The clinical practice location demographics are presented in Table 1. There were seven clinical practice location groups represented in our sample because of physicians practicing in multiple locations. Physicians who reported practicing in multiple locations that included ruralpractice (3\%), were excluded from location of practice group comparisons because of an inability to group them as rural or urban/suburban practice.

Other demographic characteristics of the sample are presented in Table 2. A majority of respondents were male and

Table 1

Clinical practice location demographics of sample

\begin{tabular}{|c|c|c|}
\hline $\begin{array}{l}\text { Clinical practice location } \\
(n=214)\end{array}$ & $N$ & $\%$ \\
\hline Suburban & 83 & $39 \%$ \\
\hline Rural & 69 & $32 \%$ \\
\hline Urban & 36 & $17 \%$ \\
\hline 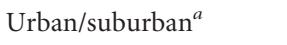 & 19 & $9 \%$ \\
\hline Suburban/rural ${ }^{b}$ & 4 & $1.5 \%$ \\
\hline Urban/suburban/rural ${ }^{b}$ & 2 & $1 \%$ \\
\hline Urban/rural $^{b}$ & 1 & $0.5 \%$ \\
\hline
\end{tabular}


Table 2

Demographic characteristics of sample and proportion of physicians who ever referred for an indication of hereditary breast cancer by demographic characteristics

\begin{tabular}{|c|c|c|c|c|}
\hline & \multirow{2}{*}{$\begin{array}{c}\text { Sample } \\
\text { distribution, }{ }^{a} \\
\%(N)\end{array}$} & \multirow{2}{*}{$\begin{array}{l}\text { Ever- } \\
\text { referred, } \\
\%\end{array}$} & \multicolumn{2}{|c|}{$\begin{array}{l}\text { Logistic } \\
\text { regression }\end{array}$} \\
\hline & & & $\begin{array}{l}\text { Odds } \\
\text { ratio }\end{array}$ & $95 \% \mathrm{CI}$ \\
\hline \multicolumn{5}{|l|}{ Gender $^{b}$} \\
\hline Female & $36.2(75)$ & 61.3 & 2.41 & $1.2-4.8$ \\
\hline Male & $63.8(132)$ & 45.0 & & \\
\hline \multicolumn{5}{|l|}{ Specialty $^{c}$} \\
\hline Specialists & $33.8(70)$ & 80.0 & 6.7 & $3.3-13.7$ \\
\hline Generalists & $66.2(137)$ & 36.0 & & \\
\hline \multicolumn{5}{|c|}{ Graduation from medical school $^{c}$} \\
\hline$<1990$ & $65.2(135)$ & 59.3 & 3.1 & $1.5-6.2$ \\
\hline$\geq 1990$ & $34.8(72)$ & 35.2 & & \\
\hline \multicolumn{5}{|l|}{ Location of practice ${ }^{b}$} \\
\hline Urban/suburban & $66.7(138)$ & 58.7 & 2.3 & $1.2-4.6$ \\
\hline Rural & $33.3(69)$ & 35.3 & & \\
\hline
\end{tabular}

CI, confidence interval.

${ }^{a}$ Excludes physicians who practice in multiple locations that include ruralpractice $(3 \%)$.

${ }^{b} P<0.05$ for "Ever-referred" \%.

${ }^{c} P \leq 0.001$ for "Ever-referred" \%.

generalists, including family practice, internal medicine, and general practice. Year of graduation from medical school ranged from 1949 to 1999, with a median graduation year of 1985. Respondents differed from nonrespondents by specialty $(P<0.05)$. The response rate was highest for specialists, including oncology (57\%), obstetrics and gynecology (39\%), and general surgery $(30 \%)$, and lowest for generalists, including family practice (22\%), internal medicine (19\%), and general practice (15\%). Further differences between respondents and nonrespondents could not be evaluated due to a lack of demographic information for nonrespondents.

\section{Referral practices}

Approximately half (51\%) of the study population reported having ever referred for an indication of hereditary breast cancer. Table 2 presents the proportion of respondents who ever referred by demographic characteristics. Logistic regression was used to determine if clinical practice location affected whether or not physicians had ever referred. Gender, specialty, and year of graduation from medical school were included as possible confounders. All variables were statistically significant. Female providers, specialists, and physicians graduating before 1990 were more likely to have ever referred. After controlling for these variables, urban/suburban-practice physicians were over twice as likely to have ever referred for an indication of hereditary breast cancer than rural-practice physicians. Of physicians who reported ever referring for this in- dication, the referral frequency in the last twelve months was greater among urban/suburban-practice as compared to ruralpractice $(P<0.05)$.

Participants who reported referring at least one patient for hereditary breast cancer evaluation indicated that the most common reason for referral was family history of cancer (87\%), followed by patient interest (57\%), patient history of cancer (36\%), surgical decision-making (25\%), and decisions regarding hormone use (17\%). Rural-practice physicians were more likely to refer because of patient interest $(P<0.05)$, whereas urban/suburban-practice physicians were more likely to refer for patient history of cancer $(P<0.05)$. Other reasons for referral did not differ in frequency between clinical practice location groups.

Overall, respondents reported most often that they would refer to a genetic counselor (48\%) for patients in need of genetic services for hereditary breast cancer, followed by an oncologist (36\%), geneticist (34\%), and surgeon (13\%). Ruralpractice physicians were more likely to refer to an oncologist $(P<0.05)$, whereas urban/suburban-practice physicians were more likely to refer to a genetic counselor $(P<0.05)$. Of all the respondents, $12 \%$ reported not knowing to whom they would refer patients in need of genetic services for hereditary breast cancer, irrespective of clinical practice location.

Approximately half of the sample indicated that they had never referred a patient for hereditary breast cancer evaluation. Of those physicians, a majority (59\%) indicated the reason to be that they had no need for such services, whereas $41 \%$ reported that barriers to referral exceeded motivations. The reason for never having referred did not differ by clinical practice location.

\section{Referral attitudes}

Respondents were asked to rate the strength of influence for 10 motivations to referral for hereditary breast cancer. The strongest motivations for referral overall were "patient interest," "genetic testing," and "access to expertise." The least influential motivations for referral were "time saving," "malpractice concerns," and "research studies." There was no difference in the strength of influence for any motivations between clinical practice locations.

Respondents also rated the strength of influence for 10 barriers to referral for hereditary breast cancer. Table 3 presents the influence scores of individual barriers by clinical practice location. Several barriers were more influential among ruralpractice physicians, including "distance of services," "lack of awareness of services," "lack of effective risk reduction or clinical management," and "patients not interested" $(P<0.05)$.

\section{DISCUSSION}

As anticipated, we identified differences in physician referral practices and attitudes based on clinical practice location. Urban/suburban-practice physicians were over two times as likely to have ever referred for genetic services for hereditary breast cancer than rural-practice physicians after controlling for de- 
Table 3

Barriers to genetics referral by clinical practice location

\begin{tabular}{|c|c|c|c|}
\hline & \multicolumn{2}{|c|}{ Mean influence value $^{a}$ (SD) } & \multirow[b]{2}{*}{$P$} \\
\hline & $\begin{array}{l}\text { Urban/suburban } \\
\text { practice }\end{array}$ & $\begin{array}{c}\text { Rural } \\
\text { practice }\end{array}$ & \\
\hline \multicolumn{4}{|l|}{ Barrier } \\
\hline Distance of services ${ }^{b}$ & $3.4(1.3)$ & $2.1(1.1)$ & $<0.0001$ \\
\hline Lack of awareness $^{b}$ & $2.5(1.4)$ & $1.9(1.1)$ & 0.001 \\
\hline $\begin{array}{l}\text { Lack of effective risk reduction } \\
\text { strategies }^{b}\end{array}$ & $3.4(1.2)$ & $3.0(1.1)$ & 0.023 \\
\hline Patients not interested ${ }^{b}$ & $3.0(1.1)$ & $2.6(1.1)$ & 0.024 \\
\hline Able to provide same services & $3.9(1.1)$ & $3.7(1.3)$ & 0.336 \\
\hline Not enough benefit & $3.8(1.1)$ & $3.6(1.1)$ & 0.351 \\
\hline Managed care plan limits & $2.6(1.4)$ & $2.7(1.3)$ & 0.639 \\
\hline Cost & $2.5(1.2)$ & $2.4(1.2)$ & 0.687 \\
\hline Risk for genetic discrimination & $2.8(1.3)$ & $2.9(1.3)$ & 0.798 \\
\hline Causes undue patient anxiety & $3.3(1.1)$ & $3.2(1.2)$ & 0.847 \\
\hline
\end{tabular}

${ }^{a}$ Likert values ranged from $1=$ "very influential" to $5=$ "not influential at all." ${ }^{b} P<0.05$.

mographic variables. We demonstrated that rural-practice physicians experience stronger barriers to referral. However, there are many other possible reasons that could contribute to the decreased frequency of referral among rural-practice physicians.

The level of urbanization has long been recognized to affect patient access to health care. There is a lower supply of physicians practicing in rural areas relative to the population size. ${ }^{30}$ On average, rural-practice physicians have shorter duration of contact with their patients, as well as fewer clinic visits, as compared to their urban counterparts. ${ }^{31}$ Rural patient populations are also less likely than urban populations to have coverage for their health care costs, particularly by private insurance..$^{30,32}$

Differences in specialty mix between clinical practice locations may also contribute to differences in referral practices. Rural regions are known to have a greater proportion of generalist physicians. In contrast, approximately $90 \%$ of specialist physicians are located in urban and suburban areas. ${ }^{32}$ Generalists have reported unique barriers to providing primary level genetic services, including time and costs, as well as demonstrating deficits in knowledge regarding hereditary breast cancer. ${ }^{19,23,27}$

Rural-practice physicians may also experience unique barriers to obtaining knowledge, a factor shown to be positively associated with genetics referral. ${ }^{23}$ A study by Mouchawar et al. ${ }^{25}$ demonstrated that rural family practice physicians have unique educational needs in obtaining information about hereditary breast cancer due to geographic isolation. In this study, requests for information via Internet-based and teleconference courses were highly associated with rural-practice. Likewise, a study by Howe et al., ${ }^{33}$ which examined differences between urban and rural management of breast cancer pa- tients, reported that rural physicians have less access to continuing education courses, other practitioners, and tumor conferences, all of which serve to educate physicians about breast cancer management.

We demonstrated that the strongest motivation for referral among all respondents was patient interest. This finding agrees with the study by Hayflick et al., ${ }^{23}$ which reported that patient or family interest was the most important factor prompting genetics referral among primary care physicians. However, when we examined the reason for past referral in the subset of our study population who had ever referred, rural-practice physicians were more likely than urban/suburban-practice to have made a referral because of patient interest ( $81 \%$ vs. $51 \%$, $P<0.05)$. One explanation for this observed difference is that although all physicians are equally motivated to refer because of patient interest, patients are more likely to raise the issue of inherited cancers in rural areas and physicians are more likely to raise the issue in urban or suburban areas. This implies that one strategy to increase referrals among rural-practice physicians is to raise awareness of genetic services among patients.

In our sample, it was surprising that physicians who graduated from medical school before 1990 were over three times more likely to have ever referred a patient. This was unexpected given past studies that have shown greater genetics knowledge among more recent medical school graduates and increased knowledge associated with referral. ${ }^{23,34}$ One explanation for our finding is that physicians who are less knowledgeable about hereditary breast cancer are more likely to seek the advice of specialists through patient referral. Therefore, if we aim to increase physician knowledge of hereditary breast cancer, our results suggest that educational intervention should focus on continuing education of physicians.

Overall, our reported referral frequencies for both clinical practice location groups were greater than frequencies reported in a past study of primary care physicians by Hayflick et al. ${ }^{23}$ They reported that among internists and obstetrician/gynecologists, only $3 \%$ and $27 \%$, respectively, would refer for this indication. Our referral frequencies are likely increased because we did not differentiate between referrals to genetics and nongenetics professionals, as did the referenced study. Our results demonstrate that a substantial proportion of referrals for hereditary breast cancer evaluation are made to nongenetics professionals, because $55 \%$ of our respondents reported that they would refer to an oncologist or surgeon. Our data also suggest that this practice is more common among rural-practice physicians because they were more likely to refer to an oncologist than urban/suburban-practice. Based on this information, we conclude that resources for providers of genetic services for hereditary breast cancer should be aimed at both genetics and nongenetics professionals.

Of the physicians in our study who reported that they had never referred a patient for an indication of hereditary breast cancer, a majority (59\%) indicated that they had no need for such services, irrespective of practice location. It is difficult to discern whether this is truly the case or whether these physicians simply lack an understanding of the purpose and poten- 
tial benefits of genetic services for hereditary breast cancer. This result is concerning based on a recent study by Hughes et al., ${ }^{35}$ which estimated that $6 \%$ of women in a primary care setting have a significant family history of breast and/or ovarian cancer and warrant intensive evaluation. Past studies have demonstrated that physicians in multiple specialties admit a lack of confidence in their role in cancer genetic services, as well as low levels of understanding of cancer genetics. ${ }^{20,25,26}$ Our results provide further evidence for the need to educate community physicians about their role in provision of genetic services and to raise awareness about the purpose and potential benefits of genetic services for hereditary breast cancer.

One limitation to this study was the retrospective grouping of physicians into clinical practice location groups based on self-reported descriptor of practice. However, we tested the validity of our clinical practice groups by comparing physicians who met our objective definition of rural- or urban/suburban-practice, based on their county and zip code of practice, to their self-reported practice location descriptor. Among rural-practice, there was a $91 \%$ concordance in physician selfcategorization of practice location with our objective criteria and among urban/suburban-practice there was a $98 \%$ concordance. A second limitation was an overall response bias for physicians with greater interest and experience in hereditary breast cancer. However, this bias would cause a consistent overestimation of referral frequencies among all study groups, and therefore, our conclusions remain valid. Lastly, the referral practices and attitudes of physicians in this study may not be generalizable to all regions based on differences in the delivery of cancer genetics services, distance to genetics services, and patient populations.

\section{Conclusions}

This study demonstrates that women residing in rural areas of Ohio's tri-state region have unequal access to genetic services for hereditary breast cancer. Our results suggest that if genetic service providers seek to increase referrals for hereditary breast cancer among rural-practice physicians, effective strategies include establishing rural cancer genetics outreach clinics, increasing educational interventions, and raising awareness of genetic services among referring physicians, as well as patients.

This study also demonstrates that a majority of physicians who have never referred patients for hereditary breast cancer evaluation report having no need for such services. Based on traditional measures of health care efficacy in survival and disease prevention, the long-term benefit of most screening and cancer risk reduction strategies in BRCA carriers are yet unproven. However, the sole value of genetic services may not lie in the traditional definition of efficacy. Studies of the longterm outcome of genetic services for hereditary breast cancer have demonstrated benefits among at-risk women regarding decision-making about prophylactic surgery, compliance with screening recommendations, increased knowledge, decreased anxiety, increased accuracy of risk perception, and improved communication with family members. ${ }^{36-39}$ Before genetics professionals can focus on increasing physician referrals, studies are needed to assess the value physicians place on these nontraditional benefits of health services. In addition, large prospective trials of the cancer surveillance and risk-reduction options for high risk women are needed in order to further prove the benefit of genetic services for hereditary breast cancer in the traditional sense.

\section{Acknowledgments}

This research was partially supported by a grant to the Hereditary Cancer Program of Cincinnati Children's Hospital Medical Center from the Greater Cincinnati Affiliate of the Susan G. Komen Breast Cancer Foundation and Race for the Cure. We are grateful to Richard Wenstrup, MD, for his valuable input into the study design and critical reading of the manuscript.

\section{References}

1. Greenlee RT, Hill-Harmon MB, Murray T, Thun M. Cancer statistics, 2001. CA Cancer J Clin 2001;51:15-36.

2. Greene MH. Genetics of breast cancer. Mayo Clinic Proc 1997;72:54-65.

3. Whittemore AS, Gong G, Itnyre J. Prevalence and contribution of BRCA1 mutations in breast cancer and ovarian cancer: results from three U.S. population-based casecontrol studies of ovarian cancer. Am J Hum Genet 1997;60:496-504.

4. Ford D, Easton DF, Bishop DT, Narod SA, Goldgar DE. Risks of cancer in BRCA1mutation carriers: Breast Cancer Linkage Consortium. Lancet 1994;343:692-695.

5. Easton DF, Steele L, Fields $P$ et al. Cancer risks in two large breast cancer families linked to BRCA2 on chromosome 13q12-13. Am J Hum Genet 1997;61:120-128.

6. Struewing JP, Hartge $P$, Wacholder $S$ et al. The risk of cancer associated with specific mutations of BRCA1 and BRCA2 among Ashkenazi Jews. N Engl J Med 1997;336: 1401-1408.

7. Ford D, Easton DF, Stratton M, et al. Genetic heterogeneity and penetrance analysis of the BRCA1 and BRCA2 genes in breast cancer families: The Breast Cancer Linkage Consortium. Am J Hum Genet 1998;62:676-689.

8. The Breast Cancer Linkage Consortium. Cancer risks in BRCA2 mutation carriers. J Natl Cancer Inst 1999;91:1310-1316.

9. Andrykowski MA, Munn RK, Studts JL. Interest in learning of personal genetic risk for cancer: a general population survey. Prev Med 1996;25:527-536.

10. Andrykowski MA, Lightner R, Studts JL, Munn RK. Hereditary cancer risk notification and testing: how interested is the general population? J Clin Oncol 1997;15: 2139-2148.

11. Rebbeck TR, Levin AM, Eisen A et al. Breast cancer risk after bilateral prophylactic oophorectomy in BRCA1 mutation carriers. J Natl Cancer Inst 1999;91:1475-1479.

12. Rebbeck TR, Lynch HT, Neuhausen SL et al. Prophylactic oophorectomy in carriers of BRCA1 or BRCA2 mutations. N Engl J Med 2002;346:1616-1622.

13. Meijers-Heijboer H, van Geel B, van Putten WL, et al. Breast cancer after prophylactic bilateral mastectomy in women with a BRCA1 or BRCA2 mutation. $N$ Engl J Med 2001;345:159-164.

14. Hartmann LC, Schaid DJ, Woods JE et al. Efficacy of bilateral prophylactic mastectomy in women with a family history of breast cancer. N Engl J Med 1999;340:77-84.

15. King MC, Wieand S, Hale $\mathrm{K}$ et al. Tamoxifen and breast cancer incidence among women with inherited mutations in BRCA1 and BRCA2: National Surgical Adjuvant Breast and Bowel Project (NSABP-P1) Breast Cancer Prevention Trial. JAMA 2001; 286:2251-2256.

16. Fisher B, Costantino JP, Wickerham DL et al. Tamoxifen for prevention of breast cancer: report of the National Surgical Adjuvant Breast and Bowel Project P-1 Study. J Natl Cancer Inst 1998;90:1371-1388.

17. Kauff ND, Satagopan JM, Robson ME et al. Risk-reducing salpingo-oophorectomy in women with a BRCA1 or BRCA2 mutation. N Engl J Med 2002;346:1609-1615.

18. Harris R, Harris HJ. Primary care for patients at genetic risk. BMJ 1995;311:579580 .

19. Watson EK, Shickle D, Qureshi N, Emery J, Austoker J. The 'new genetics' and primary care: GPs' views on their role and their educational needs. Fam Pract 1999; $16: 420-425$

20. Fry A, Campbell H, Gudmunsdottir H et al. GPs' views on their role in cancer genetics services and current practice. Fam Pract 1999;16:468-474.

21. Culver JO, Hull JL, Dunne DF, Burke W. Oncologists' opinions on genetic testing for breast and ovarian cancer. Genet Med 2001;3:120-125. 
22. Brownson RC, Davis JR, Simms SG, Kern TG, Harmon RG. Cancer control knowledge and priorities among primary care physicians. J Cancer Educ 1993;8:35-41.

23. Hayflick SJ, Eiff MP, Carpenter L, Steinberger J. Primary care physicians' utilization and perceptions of genetics services. Genet Med 1998;1:13-21.

24. Rowley PT, Loader S. Attitudes of obstetrician-gynecologists toward DNA testing for a genetic susceptibility to breast cancer. Obstet Gynecol 1996;88(4 Pt 1):611-615.

25. Mouchawar J, Klein CE, Mullineaux L. Colorado family physicians' knowledge of hereditary breast cancer and related practice. J Cancer Educ 2001;16:33-37.

26. Escher M, Sappino AP. Primary care physicians' knowledge and attitudes towards genetic testing for breast-ovarian cancer predisposition. Ann Oncol 2000;11:11311135.

27. Friedman LC, Plon SE, Cooper HP, Weinberg AD. Cancer genetics: Survey of primary care physicians' attitudes, and practices. J Cancer Educ 1997;12:199-203.

28. Guilbert P, Cheater F. Health visitors' awareness and perception of clinical genetic services. J Med Genet 1990;27:508-511.

29. Miller SA. An Assessment of Primary Care Physicians' Attitudes Toward Genetic Testing and Genetic Counseling. [thesis]. University of Cincinnati, 1995.

30. Eberhardt MI, DD Makuc DM et al. Urban and Rural Health Chartbook, United States, 2001. Hyattsville, MD: National Center for Health Statistics, 2001.

31. U.S. Congress, Office of Technology Assessment. Health Care in Rural America (OTA-H-434). Washington DC: U.S. Government Printing Office, 1990.
32. Rural Information Center Health Service (RICHS), 2002. Available at: http://www. nal.usda.gov/ric/richs. Accessed December 1, 2002.

33. Howe HL, Katterhagen JG, Yates J, Lehnherr M. Urban-rural differences in the management of breast cancer. Cancer Causes Control 1992;3:533-539.

34. Hofman KJ, Tambor ES, Chase GA, Geller G, Faden RR, Holtzman NA. Physicians' knowledge of genetics and genetic tests. Acad Med 1993;68:625-632.

35. Hughes KS, Roche C, Campbell CT et al. Prevalence of family history of breast and ovarian cancer in a single primary care practice using a self-administered questionnaire. Breast J 2003;9:19-25.

36. Pritzlaff M. The Impact of Genetic Counseling on Clinical Decision Making Among Women Evaluated for Hereditary Breast and Ovarian Cancer Risk [thesis]. University of Cincinnati, 2001

37. Bernhardt BA, Biesecker BB, Mastromarino CL. Goals, benefits, and outcomes of genetic counseling: client and genetic counselor assessment. Am J Med Genet 2000 94:189-197.

38. Meiser B, Butow PN, Barratt AL et al. Long-term outcomes of genetic counseling in women at increased risk of developing hereditary breast cancer. Patient Educ Couns 2001;44:215-25.

39. Cull A, Anderson ED, Campbell S, Mackay J, Smyth E, Steel M. The impact of genetic counselling about breast cancer risk on women's risk perceptions and levels of distress. Br J Cancer 1999;79:501-508. 